\title{
Pelatihan Mendeley Bagi Para Peneliti Muda Kota Pekanbaru
}

\author{
Muthia Anggraini*1, Alfian Saleh ${ }^{2}$ \\ 1,2Program Studi Teknik Sipil, Fakultas Teknik, Universitas Lancang Kuning \\ *e-mail: muthia@unilak.ac.id ${ }^{1}$, alfian.saleh@unilak.ac.id ${ }^{2}$
}

\begin{abstract}
The use of references or citation managers such as Mendeley, which has begun to be encouraged for students who are preparing their Final Projects, can make it easier for students to revise their proposals or Final Projects and can understand more deeply about Final projects revisions. In the final project, students are limited in accessing popular references. There are still many students who are members of the Final Project research group who are overwhelmed and some even don't know about the Mendeley application. In the service activity that will be carried out at the Pekanbaru City Young Researcher, we as the service team provide a solution, namely providing training on the use of the Mendeley application. The results obtained from this training are that this service activity takes place smoothly, according to the specified time, and gets good attention and positive responses from all training participants. Participants can use the Mendeley application properly, starting from installing the Mendeley software on a laptop, being able to register or create an account on the Mendeley page, being able to synchronize Mendeley with Microsoft Word through the Install MS Word Plugin feature, being able to perform library searches online, and finally can create bibliography automatically with customized citation style. In conclusion, the pre-training questionnaire where the most dominant answer was $46.47 \%$ of participants had heard of Mendeley. For the questionnaire after training, $100 \%$ of participants understand the use of the application and can use the Mendeley application.
\end{abstract}

Keywords: Mendeley, Citation, Bibliography

\begin{abstract}
Abstrak
Penggunaan referensi atau citation manager seperti mendeley yang sudah mulai digalakkan bagi mahasiswa yang sedang menyusun Tugas Akhir, dapat mempermudah mahasiswa merevisi proposal atau Tugas Akhirnya dan dapat memahami lebih dalam lagi revisi Tugas Akhir. Dalam pengerjaan Tugas Akhir mahasiswa terbatas dalam mengakses referensi populer. Mahasiswa yang tergabung dalam grup research Tugas Akhir masih banyak yang kewalahan dan bahkan ada sebagian yang belum mengetahui tentang aplikasi Mendeley. Pada kegiatan pengabdian yang akan dilaksanakan pada Young Reasearcher Kota Pekanbaru, maka kami selaku tim pengabdian memberikan solusi yaitu memberikan pelatihan penggunaan aplikasi mendeley. Hasil yang didapat dari pelatihan ini adalah kegiatan pengabdian ini berlangsung dengan lancar, sesuai dengan waktu yang ditentukan serta mendapatkan perhatian yang baik serta respon positif dari seluruh peserta pelatihan. Peserta bisa menggunakan aplikasi mendeley dengan baik yaitu mulai dari menginstal software mendeley pada laptop, bisa melakukan pendaftaran atau pembuatan akun pada laman mendeley, bisa mensinkronisasikan mendeley dengan mocrosoft word melalui fitur Install MS Word Plugin, bisa melakukan penelusuran pustaka yang dilakukan secara daring, dan terakhir bisa membuat daftar pustaka secara otomatis dengan gaya sitasi yang disesuaikan. Kesimpulannya kuisoner sebelum pelatihan dimana jawaban yang paling dominan adalah 46,47\% peserta pernah mendengar tentang mendeley. Untuk kuisoner setelah pelatihan $100 \%$ peserta memahami penggunaan aplikasi dan bisa menggunaan aplikasi mendeley.
\end{abstract}

Kata kunci: Mendeley, Sitasi, Daftar Pustaka

\section{PENDAHULUAN}

Rendahnya kemampuan menulis mahasiswa dari opini dan argumentasi bahwa dalam urut keterampilan bahasa, menulis ditempatkan pada posisi terakhir. Untuk terampil dalam menulis harus memiliki kemampuan berbahasa yang sangat kompleks (Cahyani, 2010). Kemampuan dalam penulisan Tugas Akhir, Kerja Praktek, dan mempublikasikan pada jurnal nasional atau pada seminar nasional merupakan suatu kompetensi yang sangat penting bagi setiap mahasiswa dalam menyelesaikan perkuliahannya (Djamaris, 2017). 
Kondisi dari mitra yang merupakan mahasiswa Tugas Akhir, Mahasiswa Kerja Prkatek, dan Mahasiswa Tingkat Akhir yang tergabung dalam Young Reasearcher Kota Pekanbaru. Mitra umumnya belum mampu mengkutip tulisan dengan benar sehingga dalam membuat daftar pustaka sering terjadi kesalahan karena dilakukan dengan manual. Daftar pustaka mempunyai kaitan yang sangat erat dalam sebuah karya tulis ilmiah. Untuk melakukan sitasi yang dituangkan dalam teks harus juga tertuang dalam daftar pustaka, begitu juga sebaliknya (Istiana, 2013).

Untuk memudahkan mahasiswa dalam mengkutip bisa dilakukan dengan menggunakan aplikasi salah satunya dengan aplikasi Mendeley. Manajemen sitasi atau biasa disebut dengan pengelolaan referensi dari berbagai jurnal ilmiah hendaknya harus dikuasi oleh mahasiswa sehingga nantinya dapat menghasilkan penulisan yang baik (Ngibad, 2020). Mitra Young Reasearcher masih banyak yang mengalami kebingungan dalam pemakaian software Mendeley tersebut. Kemampuan memilih, mencari, menyimpan dan menentukan refernsi yang akan digunakan untu disitasi merupakan point yang sangat penting dalam penulisan Tugas Akhir, Kerja Praktek, dan artikel (Kosasi, 2019).

Mendeley merupaka suatu aplikasi yang popular yang digunakan sebagai pengelolah daftar pustaka dan dapat menjadi media untuk berbagi artikel kepada orang lain dan dalam pengutipannya dapat digunakan dengan mudah untuk mendukung penelitian (Pahmi et al., 2018). Elemen yang sangat penting dalam membuat sebuah karya tulis ilmiah adalah sitasi. Perangkat lunak seperti Mendeley merupakan soluso yang dapat dimanfaatkan oleh mitra untuk membantu dalam penulisan sitasi, sehingga membuat mahasiswa dapat mengelolah dokumen referensi yang telah dimiliki (Pramiastuti et al., 2020). Aplikasi Mendeley ini adalah merupakan salah satu jenis perangkat lunak yang penggunaannya cukup mudah untuk dipakai bagi orang awam sehingga aplikasi ini menjadi aplikasi favorit bagi penulis (Yusdita \& Utomo, 2019).

Penggunaan citation manager pada aplikasi Mendeley sudah mulai digalakkan bagi mahasiswa dalam penyusunan Tugas Akhir, laporan Kerja Praktek, sehingga dapat mempermudah mahasiswa dalam merevisinya. Permasalahan yang dihadapi mitra sehingga membuat tim kami membantu memberi pelatihan dalam penggunaan aplikasi Mendeley (Patak \& Akib, 2015).

Kelebihan dalam menggunakan aplikasi Mendeley ini cukup banyak, diantaranya mahasiswa nanti mampu menampilkan sumber refernsi nantinya pada tulisan dengan mengikuti kaidah penulisan yang benar sesuai dengan jenis daftar pustaka yang diminta. Mahasiswa juga dapat menjamin pembaca nantinya dapat mengakses sumber primer tulisan dengan sangat mudah melalui fasilitas yang disediakan oleh aplikasi Mendeley dari sumber rujukan (Triyanto et al., 2020).

Beberapa dari jenis sitasi yang umum digunakan dalam penulisan American Psyological Association (APA), Modern Language Association (MLA), American Medical Association (AMA), Turabian, Cgicago, dan lain sebagainya. Perbedaan ini umumnya mahasiswa yang sedang menyusun Tugas Akhir belum mengetahui perbedaan penulisan pustaka dengan gaya sitasi yang disebutkan diatas (Imam et al., 2019).

\section{METODE}

Metode yang dilakukan dalam kegiatan ini adalah :

1) Memberikan semangat serta motivasi epada mitra tentang sangat pentingnya tata cara ataupun etika dalam publikasi ilmiah. Metode yang digunakan adalah ceramah, diskusi/ Tanya jawab, serta tutorial penggunaan aplikasi mendeley.

2) Melakukan pelatihan terhadap mitra tentang aplikasi Mendeley secara maksimal. 
Tahapan pelaksanaan dari pengabdian ini dilakukan dalam 4 sesi yaitu sesi pertama mengisi kuisoner sebelum pelatihan dilaksanakan, sesi kedua yaitu sesi ceramah dan disertai dengan diskusi dan Tanya jawab materi yang disampaikan. Sesi ketiga tutorial penggunaan aplikasi Mendeley yang langsung didampingi oleh tim pengabdian. Terakhir sesi keempat adalah pengisian kuisoner setelah pelatihan.

Lokasi pelatihan dilaksanakan di Program Studi Teknik Sipil Universitas Lancang Kuning, dengan jumlah peserta sebanyak 15 orang.

\section{HASIL DAN PEMBAHASAN}

Sebelum masuk pada tutorial penggunaan aplikasi mendeley, peserta terlebih dahulu diberikan pemahaman tentang mendeley, fungsi dan kegunaan dari mendeley agar peserta bisa dengan mudah pada saat pelaksanaan penggunaan aplikasinya.

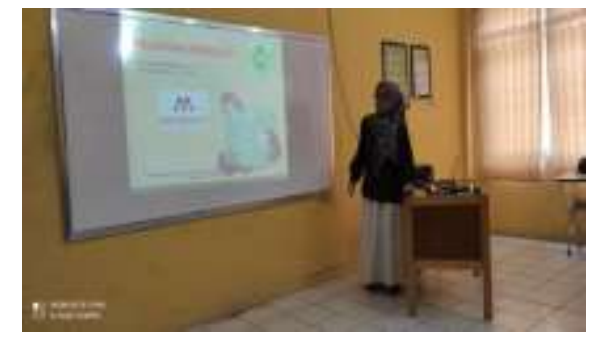

Gambar 1. Penyampaian materi pelatihan

Penyampaian materi diberikan dalam berupa slide yang disampaikan langsung pada peserta dan terakhir dilakukan diskusi tanya jawab. Peserta sangat antusias mengikuti pelatihan ini, karena diakhir sesi penyampaian materi banyak peserta memberikan pertanyaan mengenai materi yang disampaikan.

Untuk dapat melakukan evaluasi kegiatan pengabdian ini, maka kami selaku tim pengabdian melakukan penyebaran kuisoner kepada seluruh peserta pelatihan. Kuisoner diberikan sebelum dan setelah dilaksanakan pelatihan.

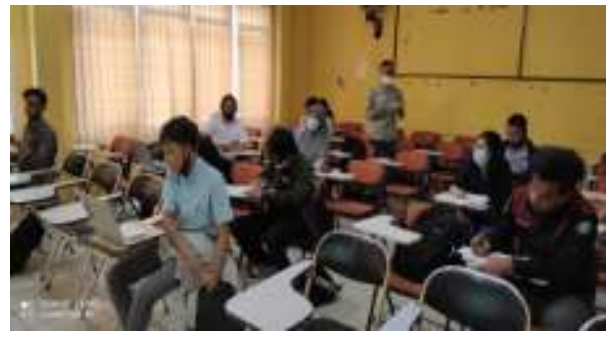

Gambar 2. Pendistribusian kuisoner pelatihan

Penyebaran kuisiner ini berfungsi untuk melihat sejauh mana peserta memahami tentang materi yang disampaikan. Peserta yang mengikuti pelatihan ini berjumlah 15 orang peserta.

Materi pertanyaan yang diberikan kepada peserta sebelum dilakukan pelatihan adalah :

1. Mengetahui tentang aplikasi Mendeley.

2. Penggunaan aplikasi Mendeley.

Untuk soal kuisoner yang diberikan setelah dilakukan pelatihan adalah :

1. Memahami aplikasi Mendeley.

2. Penggunaan aplikasi Mendeley memudahkan dalam penulisan Tugas Akhir, Kerja Prkatek, dan pembuatan artikel serta memudahkan dalam pembuatan daftar pustaka. 
Pelaksanaan penggunaan aplikasi Mendeley yaitu sebelumnya Aplikasi ini diberikan sehari sebelum melaksanakan pelatihan. Aplikasi diberikan kepada ketua mitra pengabdian untuk didistribusikan kepada anggota pelatihan. Sehingga pada saat melaksanakan pelatihan peserta telah menginstal aplikasi pada laptopnya. Tutorial penggunaan aplikasi diberikan kepada peserta setelah dilakukan penyampaian materi diawal kegiatan.

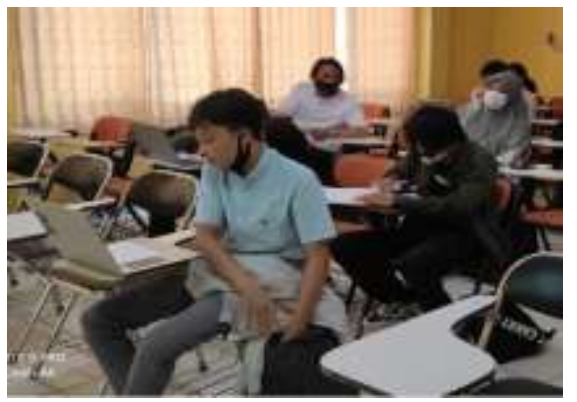

Gambar 3. Tutorial penggunaan aplikasi mendeley

Langkah awal untuk memulai menggunakan aplikasi Mendeley pada desktop adalah menginstall Ms. Word Plugin terlebih dahulu. Ini dilakukan agar nantinya dapat mensinkronkan dengan Ms. Word. Setelah itu peserta melakukan konfigurasi dalam menentukan letak dari direktori penyimpanan file, menggorganisasikan semua file dokumen yang ada, mengelola file berdasarkan tahun, merubah nama file, mengelola nama penulis, judul, tahun, dan nama jurnalnya. Sebelum memulai tutorial aplikasi Mendeley, peserta diminta mnegumpulkan terlebih dahulu referensi untuk digunakan dalam aplikasi.

Pelaksanaan pengabdian kepada masyarakat yang dilakukan oleh tim kami yaitu berupa Pelatihan Mendeley Bagi Mahasiswa Young Researcher Kota Pekanbaru. Kegiatan ini diawali dengan penyampaian materi, pemberian kusioner, dan tutorial penggunaan aplikasi mendeley. Peserta yang mengikuti pelatihan ini berjumlah 15 (lima belas) orang. Kegiatan dilakukan dengan sistem tatap muka tetapi tetap mengikuti protokoler kesehatan dengan menggunakan masker, jaga jarak, dan menyediakan handsanitazer di dalam ruangan pelatihan.

Hasil kuisoner yang diberikan kepada peserta pelatihan sebelum dilakukan pelatihan hasilnya sebagai berikut :

Tabel 1. Hasil kuisoner sebelum pelatihan

\begin{tabular}{cccc}
\hline No & \multicolumn{2}{c}{ Jawaban Kuisoner } & Persentase (\%) \\
& Pernah & Tidak pernah & \\
\hline 1 & 7 & 8 & 46,67 \\
2 & 2 & 13 & 13,33 \\
3 & 5 & 9 & 35,71 \\
4 & 1 & 14 & 6,67 \\
\hline
\end{tabular}

Tabel diatas hasil pengisian kuisoner peserta pelatihan yang berjumlah 15 orang sebelum dilakukannya pelatihan. Isi dari kuisoner sebelum pelatihan adalah :

1. Apakah pernah mendengarkan tentang mendeley?

2. Apakah mengetahui apa itu mendeley?

3. Apakah bisa mengaplikasikan penggunaan mendeley?

4. Apakah pernah menggunakan mendeley?

Untuk lebih jelas hasil kuisoner dari peserta pelatihan sebelum dilaksanakannya pelatihan mendeley dapat dilihat pada Gambar berikut : 


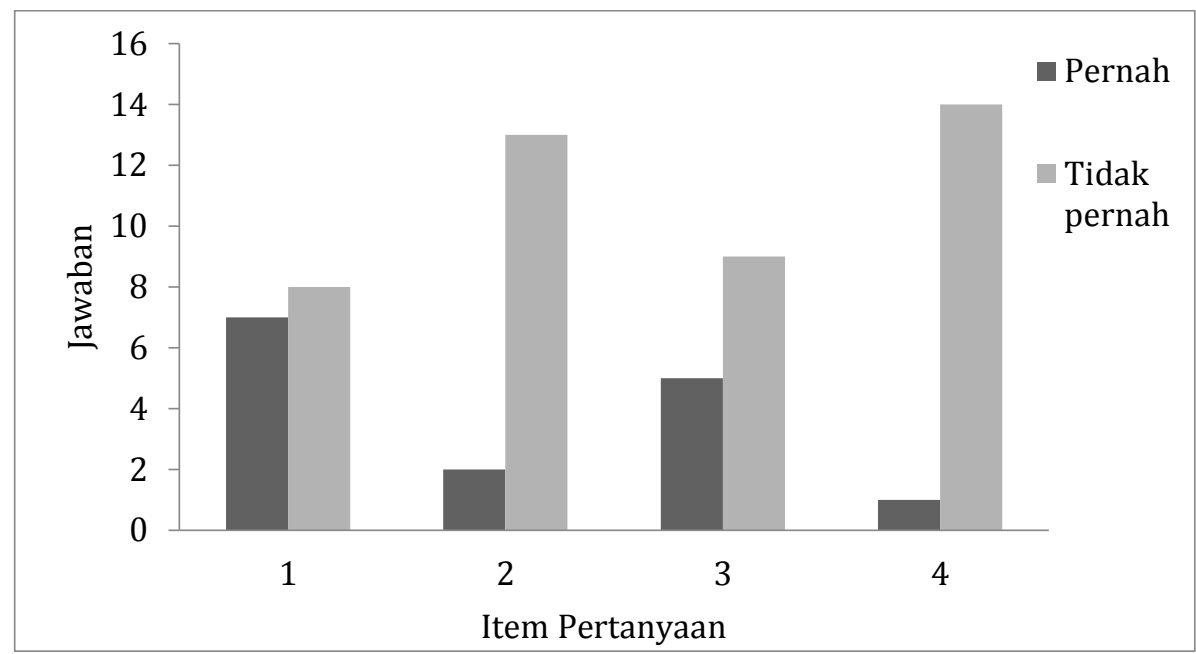

Gambar 4. Grafik persentase jawaban kuisoner sebelum dilakukan pelatihan

Dari gambar diatas dapat dilihat bahwa untuk pertanyaan pertama tentang pernah mendengar tentang mendeley sekitar $46,67 \%$ peserta yang pernah mendengar tentang mendeley. Pertanyaan kedua tentang mengetahui tentang mendeley hasilnya 13,33\% peserta yang mengetahuinya. Pertanyaan ketiga tentang bisa menggunakan aplikasi mendeley hasilnya $35,71 \%$ peserta bisa menggunakannya. Untuk pertanyaam terakhir tentang pernah menggunakan aplikasi mendeley hasilnya 6,67\% peserta yang pernah menggunakannya. Dari 4 pertanyaan yang diberikan yang dominan dari peserta pelatihan adalah hamper sebagian dari peserta pernah mendengar tentang aplikasi mendeley, yaitu 7 orang menjawab pernah dan 8 orang peserta menjawab tidak pernah. berikut :

Hasil kuisoner yang diberikan kepada peserta setelah dilakukan pelatihan adalah sebagai Tabel 2. Hasil kuisoner setelah pelatihan

\begin{tabular}{cccc}
\hline No & \multicolumn{2}{c}{ Jawaban Kuisoner } & Persentase (\%) \\
& Ya & Tidak & \\
\hline & & & \\
1 & 15 & 0 & 100 \\
2 & 15 & 0 & 100 \\
3 & 15 & 0 & 100 \\
4 & 15 & 0 & 100 \\
\hline
\end{tabular}

Tabel diatas hasil pengisian kuisoner peserta pelatihan yang berjumlah 15 orang setelah dilakukannya pelatihan. Isi dari kuisoner setelah pelatihan adalah :

1. Apakah sudah mengetahui apa itu mendeley?

2. Apakah sudah bisa mengaplikasikan penggunaan mendeley?

3. Apakah mendeley bisa membantu dalam penulisan TA/ KP ?

4. Apakah pelatihan mendeley dapat memudahkan dalam pembuatan daftar pustaka?

Untuk lebih jelas hasil kuisoner dari peserta pelatihan setelah dilaksanakannya pelatihan mendeley dapat dilihat pada Gambar berikut : 


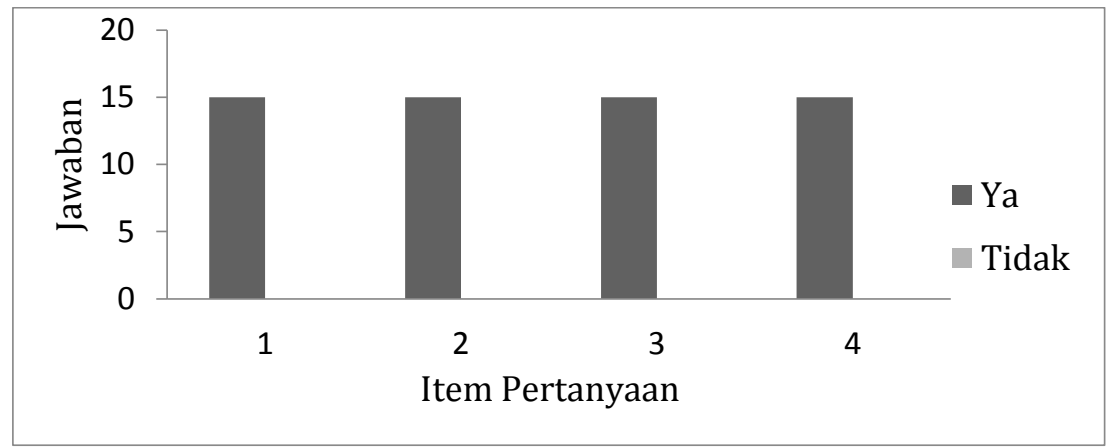

Gambar 5. Grafik persentase jawaban kuisoner setelah dilakukan pelatihan

Dari gambar diatas dapat dilihat untuk pertanyaan pertama tentang sudah mengetahui aplikasi mendeley hasilnya $100 \%$ peserta menjawab sudah mengetahui. Untuk pertanyaan kedua hasilnya $100 \%$ peserta menjawab bisa menggunakan aplikasi mendeley. Untuk pertanyaan ketiga hasilnya $100 \%$ peserta menjawab mendeley bisa membantu dalam penulisan TA/ KP. Untuk pertanyaan terakhir hasilnya $100 \%$ peserta pelatihan mendeley memudahkan dalam pembuatan daftar pustaka. Dari 4 pertanyaan yang diberikan 15 peserta memahami penggunaan aplikasi mendeley.

Hasil penilaian 15 peserta pelatihan selama mengikuti pelatihan mendeley ini dapat dilihat pada Tabel berikut:

Tabel 3. Hasil Penilaian Peserta Pelatihan

\begin{tabular}{clc}
\hline No & \multicolumn{1}{c}{ Nama Peserta } & Nilai \\
\hline 1. & Ummy Mahrani Siregar & Baik \\
2. & Mayori & Baik \\
3. & Dumaria & Baik \\
4. & Iwan Ananda Siregar & Cukup Baik \\
5. & Bagas Adrian Pratama & Cukup Baik \\
6. & Febrilla Simanjuntak & Cukup Baik \\
7. & Ahmad Alwi & Baik \\
8. & Dandi & Baik \\
9. & Lamsihar Sihombing & Baik \\
10. & Suci Kanida Br. Sinaga & Baik \\
11. & Muhamad Redho & Baik \\
12. & Wahyudi & Baik \\
13. & Robi Fadrillah & Cukup Baik \\
14. & Muhaimin & Cukup Baik \\
15. & Amsal Manogu & Baik \\
\hline
\end{tabular}

Penilaian yang dilakukan pada peserta dilihat dari keaktifan pada saat mengikuti pelatihan serta pelaksanaan pada saat penggunaan aplikasi mendeley yang diberian. Nilai baik diberikan apabila peserta aktif pada saat pelatihan dan selesai mengerjakan tutorial yang diberikan.

Nilai kumulatif seluruh peserta pelatihan dapat dilihat pada Tabel berikut:

Tabel 4. Rekapan Nilai Peserta Pelatihan

\begin{tabular}{llcc}
\hline No & Nilai & Jumlah & Persentase (\%) \\
\hline 1. & Baik & 10 & 66,67 \\
2. & Cukup Baik & 5 & 33,33 \\
\hline
\end{tabular}


Tabel diatas terlihat bahwa dari 15 peserta pelatihan 10 orang mendapatkan nilai Baik dan 5 orang mendapatkan nilai Cukup Baik. Untuk lebih jelas hasil penilaian peserta pelatihan dapat dilihat pada gambar berikut:

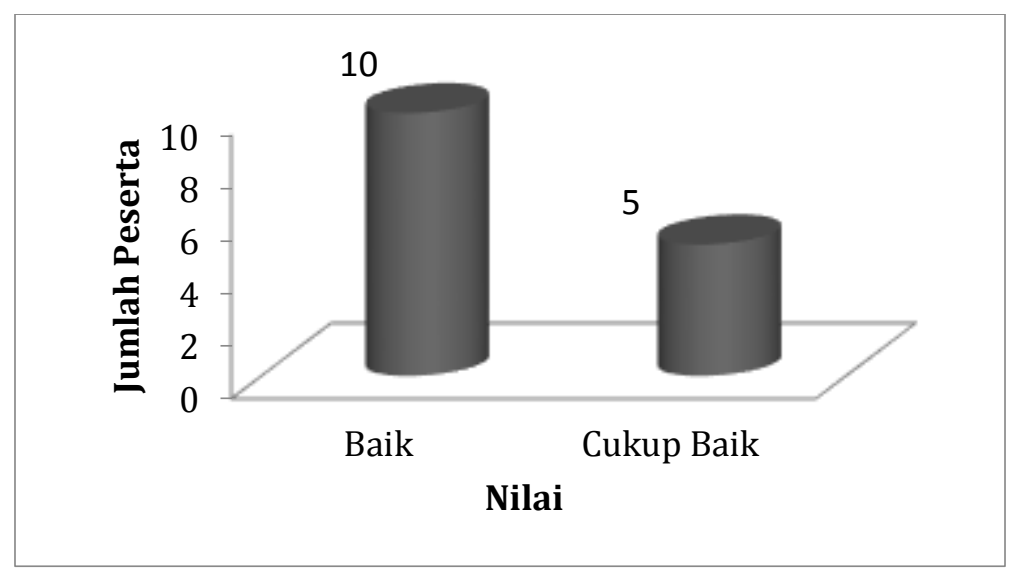

Gambar 6. Grafik persentase nilai peserta pelatihan

Dari gambar diatas dapat dilihat bahwa dari 15 peserta pelatihan $66,67 \%$ mendapatkan nilai Baik dan 33,33\% mendapatkan nilai Cukup Baik. Hal ini menunjukkan bahwa lebih dari setengah jumlah peserta dapat mengaplikasikan mendeley dengan baik.

Dari hasil pemantau kami tim pengabdian, dimana dari tutorial pengabdian yang telah diberikan pada saat pelatihan secara keseluruhan peserta bisa menggunakan aplikasi tersebut. Berikut kami ambil 3 sampel dari 15 peserta yang telah bisa menggunakan aplikasi mendeley yaitu:

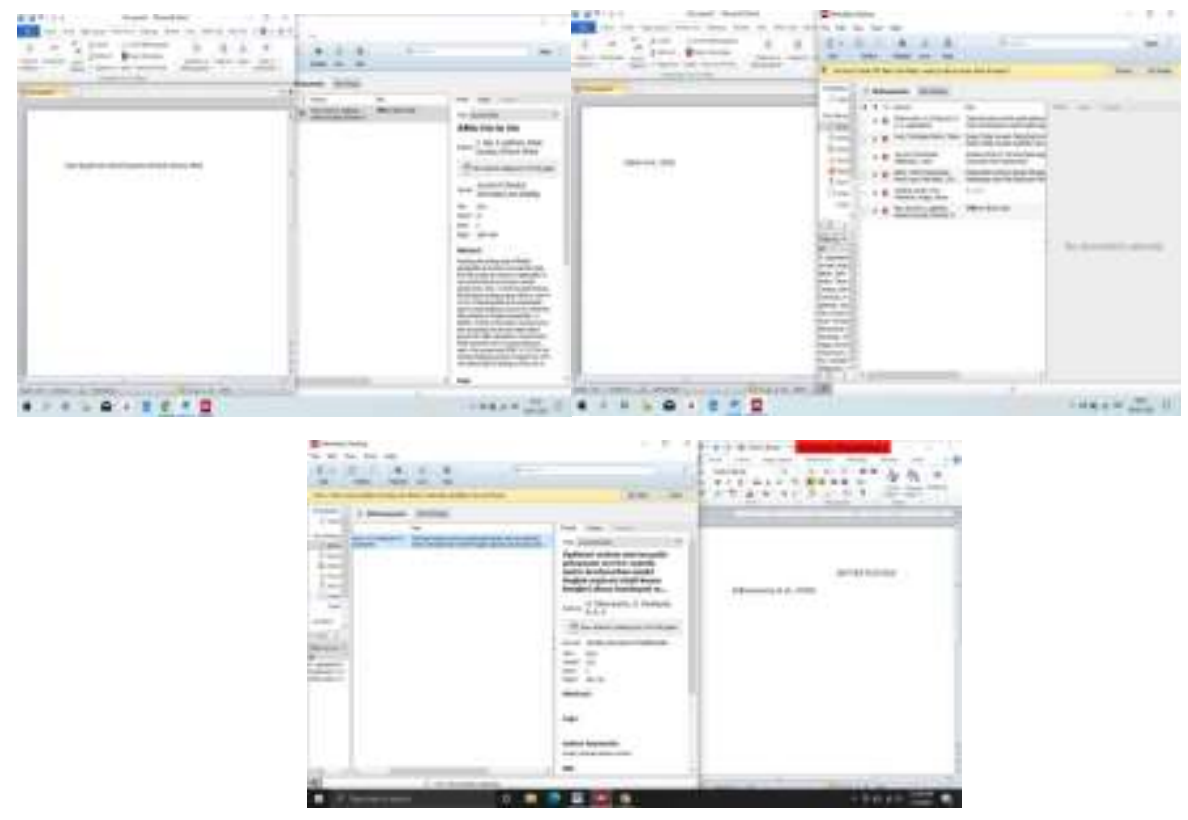

Gambar 7. Hasil penggunaan aplikasi mnedeley dari salah satu peserta pelatihan

Dari gambar diatas dapat dilihat bahwa peserta pelatihan bisa mengaplikasikan penggunaan mendeley, mulai dari memasukkan kedalam pustaka pribadi dalam aplikasi dan membuat daftar pustaka dari aplikasi tersebut.

Secara keseluruhan kegiatan pengabdian ini berlangsung dengan lancar, sesuai dengan waktu yang ditentukan serta mendapatkan perhatian yang baik serta respon positif dari seluruh peserta pelatihan. Peserta bisa menggunakan aplikasi mendeley dengan baik yaitu mulai dari menginstal software mendeley pada laptop, bisa melakukan pendaftaran atau pembuatan akun pada laman mendeley, bisa mensinkronisasikan mendeley dengan microsoft word melalui fitur 
Install MS Word Plugin, bisa melakukan penelusuran pustaka yang dilakukan secara daring, dan terakhir bisa membuat daftar pustaka secara otomatis dengan gaya sitasi yang disesuaikan.

\section{KESIMPULAN}

Kesimpulan yang didapat dari kegiatan pelatihan ini adalah :

1) Secara umum kegiatan pelatihan ini berjalan dengan baik dan lancar serta mendapat respon positif dari seluruh peserta.

2) Dari hasil kuisoner yang telah diberikan pada peserta, kuisoner sebelum pelatihan dimana jawaban yang paling dominan adalah $46,47 \%$ peserta pernah mendengar tentang mendeley. Untuk kuisoner setelah pelatihan $100 \%$ peserta memahami penggunaan aplikasi dan bisa menggunaan aplikasi mendeley. dari 15 peserta pelatihan 66,67 \% mendapatkan nilai Baik dan 33,33\% mendapatkan nilai Cukup Baik.

3) Tutorial yang diberikan bisa dilakukan dengan baik oleh peserta pelatihan.

\section{UCAPAN TERIMA KASIH}

Penulis mengucapkan terima kasih kepada Fakultas Teknik Universitas Lancang Kuning yang telah memberi dukungan financial terhadap pengabdian ini.

\section{DAFTAR PUSTAKA}

Cahyani, I. (2010). Peningkatan Kemampuan Menulis Makalah Melalui Model Pembelajaran Berbasis Penelitian pada Mata Kuliah Umum Bahasa Indonesia. Sosiohumanika: Jurnal Pendidikan Sains Sosial Dan Kemanusiaan, 3(2), 175-192.

Djamaris, A. R. A. (2017). Panduan Penggunaan Mendeley (Versi 1.17.10). In Jakarta. Universitas Bakrie.

Imam, M., Astuty, S., Samsir, A., Basra, A., \& Albi, M. F. (2019). Pelatihan Penggunaan Aplikasi Mendeley Bagi Mahasiswa Sekolah Tinggi Ilmu Pembangunan Indonesia ( STIE-PI ) Makassar Dalam Penulisan Karya Ilmiah. Prosiding Seminar Nasional Lembaga Penelitian Dan Pengabdian Kepada Masyarakat Universitas Negeri Makasar, 414-417.

Istiana, P. (2013). Membuat Sitasi dan Daftar Pustaka. Workshop Literasi Informasi Bagi Pustakawan, 1, 8.

Kosasi, S. (2019). Pemanfaatan Aplikasi Mendeley desktop Mengelola Referensi Publikasi Karya Ilmiah Mahasiswa. SNPMas: Seminar Nasional Pengabdian Pada Masyarakat, 64-74.

Ngibad, K. (2020). Pelatihan Mendeley Secara Online Bagi Mahasiswa Fikes Umaha Di Masa Pandemi Covid-19. Pengabdian Dan Pemberdayaan Nusantara, 2(1), 110-116.

Pahmi, Ardiya, Syahputra, W., Wibowo Prasetyo, A., Niah, S., \& Febtiningsih, P. (2018). Pelatihan Penggunaan Mendeley Untuk Referensi Dalam Menulis Karya Ilmiah Bagi Guru SMA Handayani Pekanbaru. Pengabdian Untuk Mu Negeri, 2(2), 35-39.

Patak, A. A., \& Akib, E. (2015). Hindari plagiat dengan Mendeley (M. B. Jafar (ed.)). Universitas Negeri Makasar.

Pramiastuti, O., Rejeki, D. S., \& Pratiwi, A. (2020). Pengenalan Dan Pelatihan Sitasi Karya Ilmiah Menggunakan Aplikasi Mendeley. Jurnal Abdimas Bhakti Indonesia, 1(1), 24-30.

Triyanto, T., Yana, R. H., \& Nurkhalis, N. (2020). Pelatihan Mendeley Pada Mahasiswa Universitas Teuku Umar. Jurnal Pengabdian Masyarakat: Darma Bakti Teuku Umar, 2(1), 7-21.

Yusdita, E. E., \& Utomo, S. W. (2019). Pelatihan Pemanfaatan Mendeley Sebagai Reference Tool Pada Artikel Ilmiah Mahasiswa Pendidikan Akuntansi Unipma. Jurnal ABDINUS : Jurnal Pengabdian Nusantara, 3(1), 36. 